\title{
Design and Analysis of Optimized Water Distribution Network at BITS Pilani, Pilani Campus
}

\author{
Harsh Srivastava, Anupam Singhal \\ Birla Institute of Technology and Science (BITS), Pilani \\ Rajasthan, India 333031 \\ f2014769@pilani.bits-pilani.ac.in; anupam_singhal@pilani.bits-pilani.ac.in
}

\begin{abstract}
Water is one of the most vital resources for human beings and therefore the water supply network is one of the most important aspects of the well-being of a community. The worth of a water supply network is to provide safe drinking water to its community in sufficient quantity, with bare-minimum quality standard, and at satisfactory pressure head with achieving economy constraint. The aim of this study is to design and analyze the water supply distribution network and to optimize the network. In the proposed network, after designing, the head loss is minimized and consequently, the cost incurred in supplying will be reduced. The study area is Birla Institute of Technology and Science (BITS) Pilani, Pilani campus. In the recent times, the population of the campus has increased which has led to higher demand and consequently higher head loss. With the increasing population, and the existing network becoming obsolete after design period, there is a need for modification in the network to maintain its use and sustainability in the longer run and this study will be helpful as its objective is to propose economical and efficient water supply distribution network and the results of this study can be incorporated directly thereby saving Time, Money and Effort. The scope of this study is not limited to study area and the principles behind this study will become the basis for the other distribution networks. The result of the study confirms that optimization of pipe network not only depends on the head losses but also on other factors like period of usage of pumps to meet the demand thereby affecting the cost incurred. The study will help water supply engineers and other consultants of the study area to use this proposed network and results for future modification required in the network of any area.
\end{abstract}

Keywords: Water supply and distribution network, water demand, Optimization, Pressure head, head loss, Power, and Efficiency.

\section{Introduction}

According to the survey, $85 \%$ of the global population has access to the piped water supply through house connections but this percentage narrows down to just more than half when it comes to India. Other report said that the water getting wasted due to leakage and theft is close to $40 \%$ in some of the cities which lead to scarce availability for the domestic and commercial purposes. This is all due to the inefficient water supply distribution network. Designing and planning of the water distribution network are as much of importance as it is for the planning of infrastructure, communities, and municipalities. Its designing and planning demand the expertise and experience of quality Civil Engineers and experienced planners who must incorporate factors like location, present demand, future growth, leakage, pressure, pipe size, pressure loss, fire-fighting flows, etc. Water supply systems get water from a variety of locations, including groundwater, surface water (lakes and rivers). The water is then, in most cases, purified, disinfected through chlorination and sometimes fluoridated. Treated water then either flows by gravity or is pumped to reservoirs, which can be elevated such as water towers or on the ground. The water is then fed into the distribution systems.

The analysis is done using the software EPANET. EPANET is software that models water distribution piping systems. EPANET is public domain software that may be freely copied and distributed. It is a Windows 95/98/NT/XP or higher program. EPANET performs an extended period simulation of the water movement and quality behavior within pressurized pipe networks.

\subsection{Objective of Study}

The pipe from overhead reservoir passes through road, colony and other distribution hurdles before reaching the individual house which results in a high head loss. The distribution network should be such that it minimizes the Head loss. 
In this study, the existing water supply network at BITS Pilani, Pilani campus, a mix of pumping and gravity system is analyzed and modeled which would be optimized for the proposed network if results demand so. In brief, the main objectives are:

- Study the existing water supply network of Birla Institute of Technology and Science Pilani, Pilani Campus.

- To study pipe report and junction report of existing network.

- To model and analyze the data using software EPANET.

- To compare the proposed network with the existing network and in terms of efficiency and cost incurred.

\section{Study Area}

The study area for this project is Birla Institute of Technology and Sciences Pilani, Pilani campus which is located 200 $\mathrm{km}$ west of Delhi and $220 \mathrm{~km}$ north of Jaipur. Its geographical coordinate defines it as latitudes $28.3640^{\circ} \mathrm{N}$ and longitudes $75.5870^{\circ} \mathrm{E}$. The total area of the campus spans over 328 acres with a population of around 6500 residing in the campus. The Institute buildings, hostels and residential quarters for staff with neatly laid out roads, lawns and gardens constitute the BITS Campus. A map of the same is given above.

The water supply data of the existing pipe network has been taken from Estate Management Unit (EMU) of the BITS Pilani, Pilani campus and image of the same has been shown below in Fig. 1. Other data has been taken either form that management unit secondary to Estate Management Unit or from Student Welfare Division (SWD). The laid campus network is shown in Fig. 2 and other data is the most recent and the distribution existing conforms to this data and is used for final verification of the results.

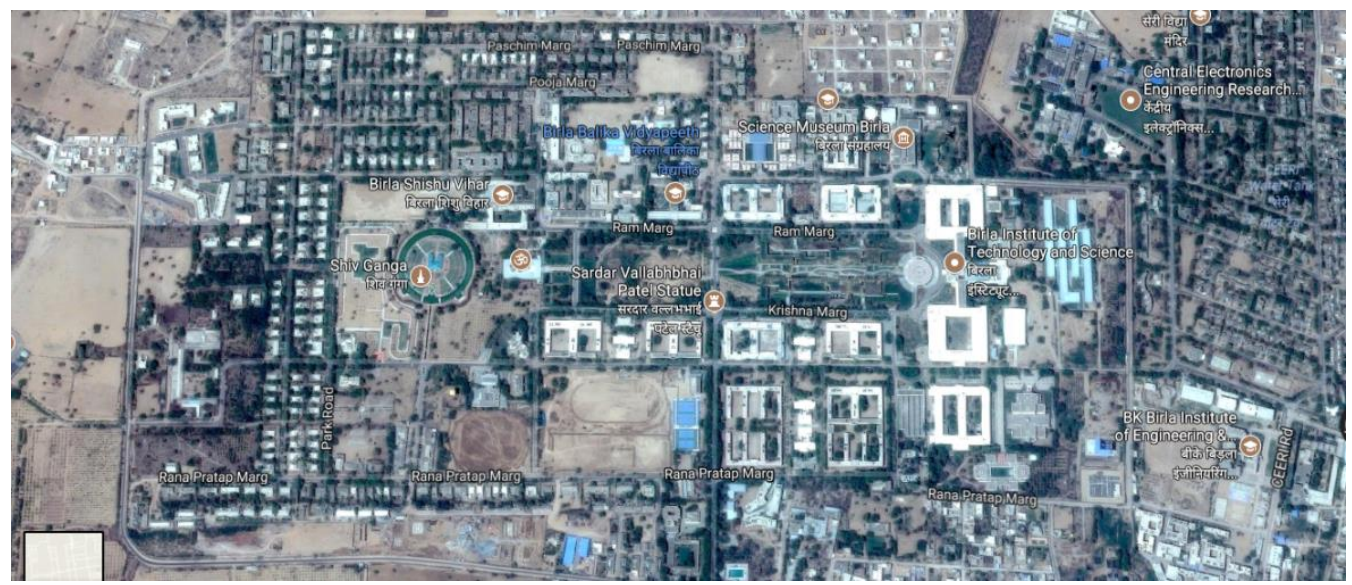

Fig. 1: BITS Pilani, Pilani campus satellite view.

\section{Literature Review}

The study of water supply distribution network has always been of keen interest to researchers, scholars, and students. In a research presented as "Analysis and Design of Water Distribution Network Using EPANET for Chirala Municipality in Prakasam District of Andhra Pradesh", [1], a network is laid according to old day's requirement and is not suitable to the future (2041) needs and demands. The network was proposed according to the master plan keeping in view the ease and accessibility of the network with roadside and straight as it will help the laying out easy and less complicated. In the study, the modeling and analysis were carried out and to incorporate the future needs of the city new location, bearing minimum cost and effort, was proposed based on EPANET software simulation result as shown in Fig. 2.

A Study on the shortage of water in some specific regions of water in Al-Diwaniya city, [2], was based on looking into the reality of supply water in the city through the distribution network. The methodology consisted of two primary steps. First was to obtain the discharge of water in the supply network along with the direction of flow in the pipe network. This analysis and simulation were performed in 1998 version of program 'Pipe++'. This step also gave the head available in each network node. Next step included the practical on-site measurement of the flow and pressure head at different ones of the network. A combined analysis showed the area suffering from shortages of water and the possible reason behind it. 
In another study, to compute pipe discharge along with head available at each node, Nielsen (1989) used different methods for the analysis of the pipe network. The main principle underlying his work was to formulate the equation for flow with the parameter, head at each node and discharge through each pipe in the form of vectors and matrix. To solve the equation and then to get the Eigenvalues, and Eigenvectors from the equation three different methods were used. The methods used were 'The Linear Graph Theory of matrix solution', 'Newton-Raphson method of iteration' and 'General Purpose Optimization algorithm', [12]. The advantage of this method of putting the flow through pipe and head available at each node in one single equation results in reduced number of equations, easy implementation, less iteration by the computer so less time, and reduced system. The drawback of this method is that sometimes it takes a number of iteration to reach the solution i.e. convergence of the system of equation is very slow. In the formula of head loss, the exponent has a value greater than unity so a part of it is taken into the resistance part of the flow and this creates a great advantage which is reducing the number of primary unknowns from $(m-n)$ to $(n / 2), n$ is the number of primary unknowns. This leads to computing of systems of equation difficult at the beginning which is handled by assuming the starting value of the system parameter. To overcome all the disadvantages and drawbacks of the system leading to solution the efficient method is by writing the generalized loop equations and solving it by means of Newton-Raphson method combined with the Linear Graph Theory as it gives easy and robust starting procedure.

Numerous research is carried in the field of water supply system and proposing the methods for the solution of such kind of problems. In the solving of the large distribution network, the uncertainties associated with the parameters may lead to large deviation in the results. All real-life problems are modeled as mathematical model approximated by engineering constraints and limitations which lead to uncertainty. Any such uncertainties are introduced through the coefficients in the formula used which sometimes depend on the surrounding or are dependent on many other nonprimitive factors lumped into one such parameter, the empirical formula used, lack of precise knowledge of the values of various parameters in the formula. These uncertainties result in the variation in the nodal values such as nodal flow and nodal pressure head. This needs to be considered in the distribution network for efficient supply through the network and for this purpose, the research proposes a two-phase methodology for the least cost design of water distribution network based on fuzzy logic and cross-entropy method, [4]. The set of values consisting of the uncertainty parameter from the fuzzy sets and the other parameters like the diameter of the individual pipe are selected from the commercially available pipe diameters by the method of cross-entropy. The research used the MATLAB and EPANET as its calculation and simulation tool to bring out the desired results. For validation of the method proposed in the research 'Hanoi Distribution Network' was used as an example and the results obtained was verified against the traditional and deterministic approach of the solution obtained from the previous research. The research concluded by confirming the objective that the proposed method of using Cross-Entropy and Fuzzy Logic method is more effective and practical.

Another study which is relevant is the one in which EPANET software was used to design and analyze the multivillage supply system with reference to technical sustainability, [10]. The study presents the hydraulic analysis of pipeline network of Punagam area near Surat city using EPANET 2.0. This study brings out the simulation of existing network in Punagam area near Surat city. The network is divided into two zones and spans in an area of 600.83 Ha and comprises 109 junctions and 144 pipes. The study aimed at analyzing the behavior of the distribution network and the pattern of flow and pressure head at various junctions and with different pipe flow. In the mentioned study it was reported that the water was taken from the source and was stored in the Ground Service Reservoir. Depending on the need it was pumped up to the Elevated Storage Reservoir and from there the water was supplied to the houses via gravity system which is in close connection with this study. The mentioned study took into account the future needs of the city and concluded that the pressure at each junction and flow through each pipe are sufficient with the demand of the city. The simulation was also checked and verified the pressure on-field. The model was checked for negative pressure generation. 


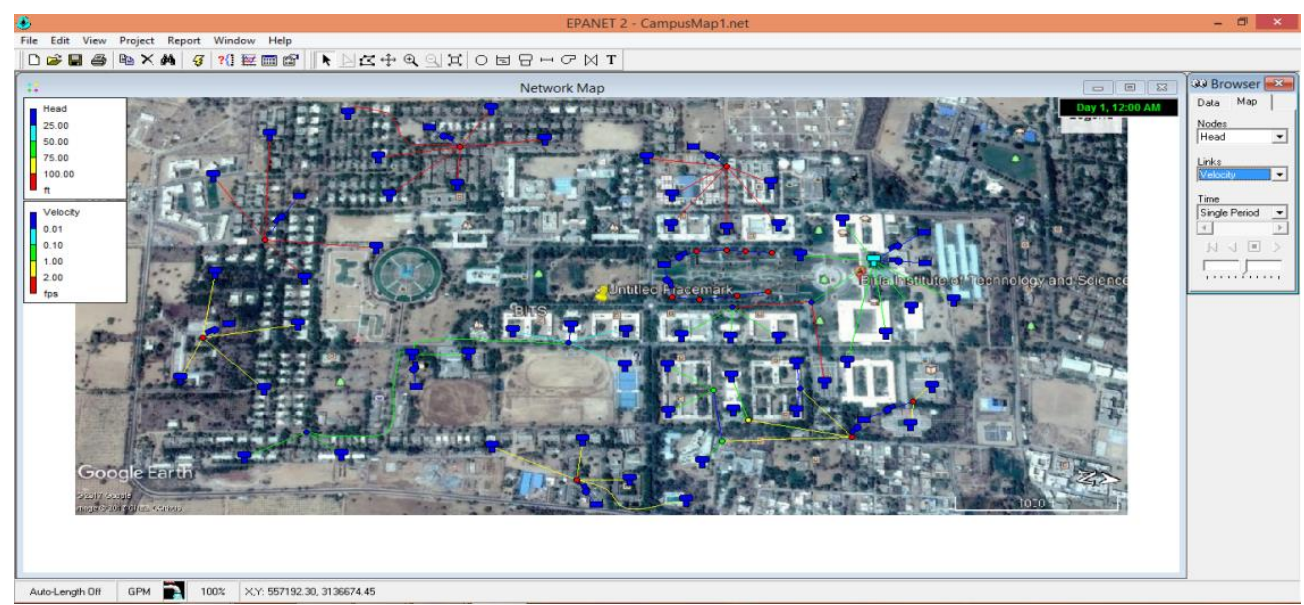

Fig. 2: Model of the campus water supply network in EPANET.

In all the literature reviewed above the objective of modeling and analysis by performing the simulation of the water supply distribution network using EPANET as a hydraulic simulation tool is carried out and the network is optimized and any improvement is suggested. This study covers all the aspect and goes further beyond to optimize and then calculate the efficiency and carries out the cost analysis thereby verifying the need and utility of Optimized network.

\section{Methodology}

\subsection{Data Input}

The data to be input as a parameter in the EPANET to specify the demand of the network at each node is given in accordance with the values specified in IS: 10500-2012. The domestic demand is taken in the study as the study area comprises quarters for livelihood. Industrial Water demand is not taken into account as the study area does not cover any area of Industry usage. The rest types of demand are taken into account depending upon the location of the individual node with 'water lost in theft and waste' taken into account on every node as it will yield a more conservative result. The quantity-demand is shown in Table 1.

\subsection{Population Forecasting}

Since in our study we have limited study area and this study aims to provide an improved network which is more efficient and economical instead of proposing a layout for the newly developed city, therefore, the population has been taken directly from the EMU unit and demand is also taken directly which the given system supply. This is reasonable as the study area comprises Institutional buildings, Hostels, Faculty and staff Quarters, and quarters allotted to those who are attached to the Institutions and Students. The number is not going to change by far large amount over the years considering the latest amendment in the admission statistics, the assumption of taking population and demand directly from the authority is reasonable.

Table 1: Various types of water demand.

\begin{tabular}{|c|c|c|}
\hline S. No & Type Of Demand & Quantity \\
\hline 1 & Domestic water demand & 135 to 225 1/h/d \\
\hline 2 & Industrial water demand & 50 litres/person/day \\
\hline 3 & Institutional and commercial water demand & 20 to 50 1/h/d \\
\hline 4 & Demand for public uses & $10 \mathrm{l} / \mathrm{h} / \mathrm{d}$ \\
\hline 5 & Fire Demand & $1 \mathrm{l} / \mathrm{h} / \mathrm{d}$ \\
\hline 6 & Water required compensating losses in wastes, thefts. & $15 \%$ of the total compensation \\
\hline
\end{tabular}




\subsection{Methods of Distribution System}

The method adopted for the study area is not strictly restricted to one single type of distribution network rather it is a mix of 'pumping' and 'gravity' system depending on the need of supply. In general, the basic principle is to supply water from the underground reservoir to an overhead local reservoir by 'Pumping System' and then to the overhead tank for consumptive usage by 'Gravity System'.

\subsection{Layouts of Distribution System}

The layout of distribution system refers to the geometrical configuration of the pipe network to provide the consumptive use of water at the given flow. More numbers of turns in the network imply more head loss. This factor is crucial in maintaining the redundancy of the system. The network should be such that it ensures the supply of water even if there is a breakdown in a part of the system. In the study area taken the layout of the distribution system is 'Radial System' with a mix of 'Dead End' type. This ensures efficient supply of water directly from the reservoir to the consumptive usage tank.

\subsection{Systems of Supply}

The water may be supplied either continuously for 24 hours of the day or may be supplied intermittently only for the peak periods during morning and evening. The intermittent supply system may sometimes lead to some saving in water consumption due to losses occurring for lesser time and more vigilant use of water by consumers. The intermittent supply system is largely employed in India and therefore has been employed in this model. The demand curve for the daily consumption has been incorporated and the same has been shown in the Fig. 3 given below. The demand attaining its peak during morning hours prior to office hours and then during the lunch hours as it contains a major population of student domain who have a synchronous routine. In order to calculate the various computational parameters like 'Head loss,' the formula adopted is 'Hazen-Williams Equation' and other formulas used only if needed. The formulas have been listed with their empirical input parameter in Table 2.

Hazen-Williams Equation:

$$
H=\left[4.72 C^{-1.85} d^{-4.87} L\right]^{*} Q^{1.85}
$$

The demand of the community is never constant and various within the day and over a period of time. The demand of the water for a community follows a pattern as every individual who is a part of the community follows same routine and lifestyle. This results in increased demand, above average, of the water supply for a particular time of the day and below average for some other time of the day. The amount of water supply should also vary as according to the need of the community. This is to ensure that the motor works for an optimum amount of time and there is minimum surcharge cost. For this, the model in the name of 'demand multiplier' is used. This gauges the variation in the requirement of water over a day and correspondingly multiplies the average demand to get the diurnal distribution for the day.

\section{Modeling and Analysis}

The modeling for the given study area has been done using Geo-Synchronisation and Geo-referencing. The campus network map was taken from the satellite image from the 'Google Earth' software and the image taken was pinned and coordinates were known and accordingly the places with the known coordinate was assigned and all the points were assigned relative to that coordinate. The total number of coordinated chosen were four for Geo-referencing. The data required for the modeling was collected from the 'Estate Management Unit' of BITS Pilani. With the data collected the modeling was carried out on EPANET by placing the tanks, reservoirs, pipes, and nodes representing the junctions. The data collected was used in giving the input to the value as 'Elevation', 'Minimum' and 'Maximum' water level, etc. Fig. 2 and Fig. 4 show the modeled campus network with and without campus background image. 


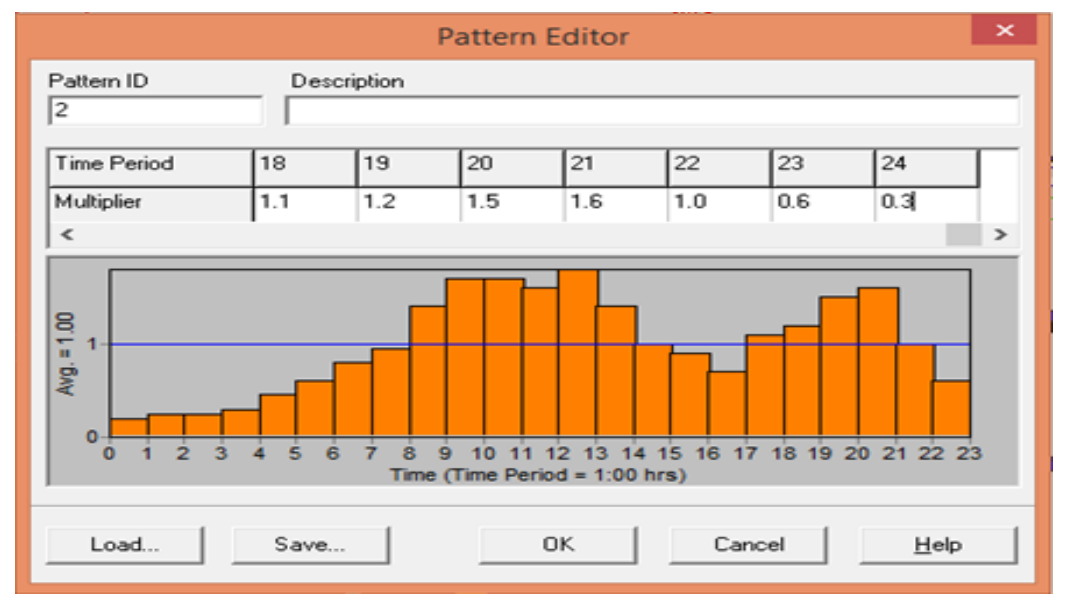

Fig. 3: Distribution of demand for flow for 24 hour period.

In the Fig. 5, it shows that velocity is varying uniformly in a pipe which is in accordance with the theoretical understanding of the pipe flow. The pressure, at the starting of the pipe flow, is highest and as the water moves in the pipe, the total pressure head available for its movement decreases due to friction between the walls of the pipe and the water that is flowing inside it resulting in the head loss. Depending on the pressure head available different pipe in the network will have different velocity and the frequency plot of the same is shown. In the Fig. 6, the pressure distribution is shown to be fairly constant which signifies uniformity of the network. The pressure throughout the pipe network is same and it is desired. A similar value of pressure in the network will result in the same pressure head available for consumption which is in accordance with the requirement of the network. Different nodes are located at different points which are at different distance from the reservoir, therefore, the head loss correspondingly will be different and the pressure head available will be different at different nodes and that is depicted in the figure in the range $35 \%-18 \%$ frequencies.

Table 2: Roughness coefficient of Pipes.

\begin{tabular}{|c|c|}
\hline Material & Hazen-Williams C \\
\hline Cast Iron & $130-140$ \\
\hline Concrete or Concrete Lined & $120-140$ \\
\hline Galvanized Iron & 120 \\
\hline Plastic & $140-150$ \\
\hline Steel & $140-150$ \\
\hline Vitrified Clay & 110 \\
\hline
\end{tabular}

\section{Results and Discussion}

The cost incurred is significantly reduced from the actual cost data obtained and the average efficiency of the motors has increased significantly which fulfills the objective of this study in terms of optimization. The total aggregate cost of all the pumps sums up to Rupees 2747.17 which is approximately $18 \%$ lower than the actual cost of the water supply and distribution network which is recorded by the administration of BITS Pilani, Pilani campus. This ensures that the study's objective of lowering the cost and improving the efficiency of the water supply and distribution network is achieved and this forms the basis for any improvement needed and any modification required should be carried out on these lines.

Fig. 7 shows that the average working efficiency of the pump lies between 70 to $85 \%$ which is indeed a good, reliable and practical condition to achieve. The efficiency varies with the amount of flow in the motor in unit time i.e. discharge and hence the efficiency range is an indirect indication of the optimum flow through and working of the motor.

The variation is not large and it indicates the optimum flow through every motor and consequently through the water supply and distribution network. 


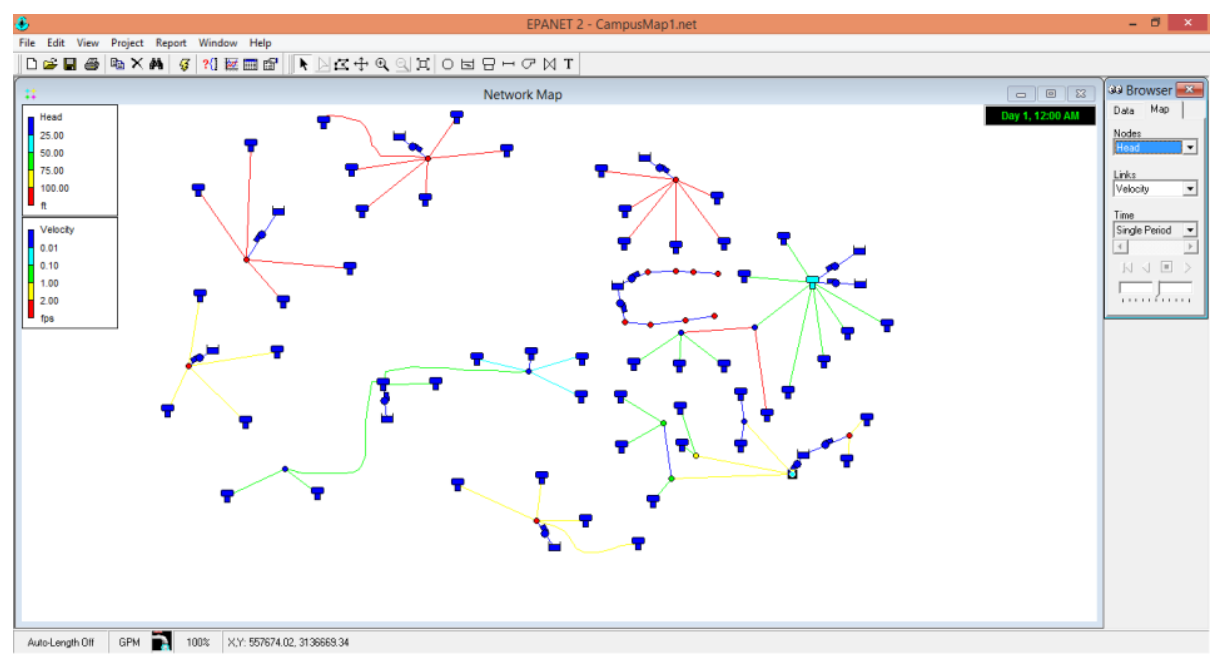

Fig. 4: Water supply network distribution representing head at nodes and velocity in pipes.

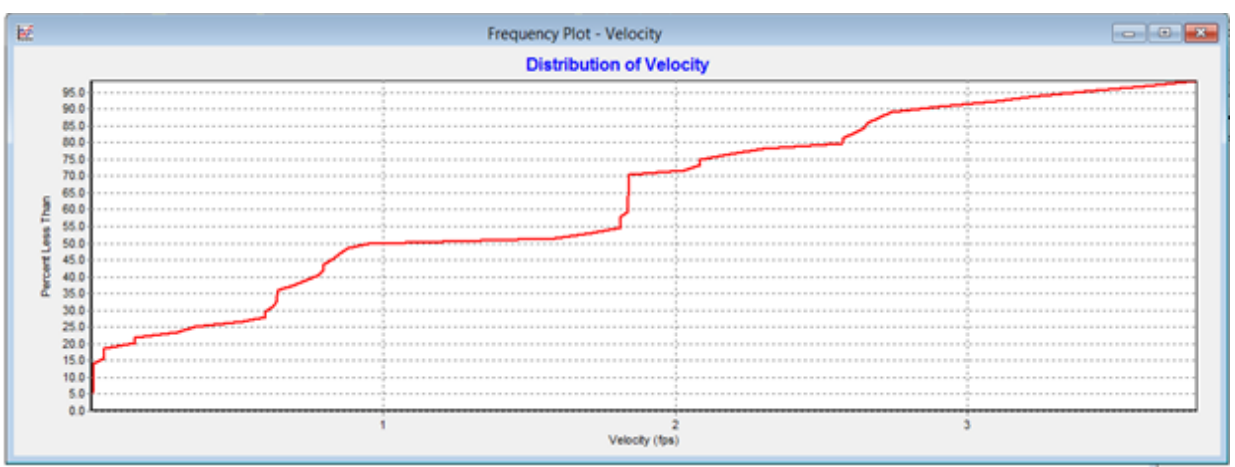

Fig. 5: Percentage Distribution of velocity less than a particular velocity in various pipes.

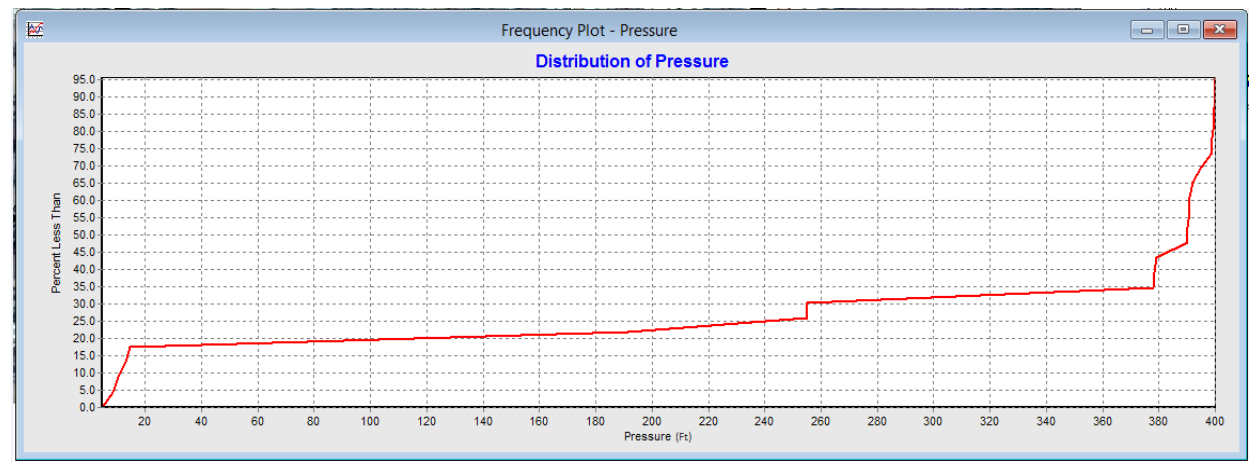

Fig. 6: Percentage Distribution of pressure less than a particular pressure at various nodes.

The Fig. 8 shows the comparative cost analysis of different pumps running over a period of time delivering the given discharge in the network. The cost analysis is carried out by EPANET and the data for the rate of electricity charge was supplied to the EPANET which was taken from the 'Rajasthan Electricity Regulatory Commission, Jaipur 2016'. The cost incurred by the pump is dependent on several factors. These include the time for which the pump operates, the power of the pump, efficiency of the pump which varies as per the flow through the pump which in turn is dependent on the demand at each node, the pump curve of the pump issued by the manufacturer. These all factors in combination give the cost that each pump generates and these values have been shown graphically and in 3-D as well. The cost variation shown is due to the fact that the amount of water supplied against the demand varies from point to point. Fig 9 depicts the percentage 
utilization of the pump. Percentage utilization refers to the percentage of the amount of water drawn through a particular reservoir.

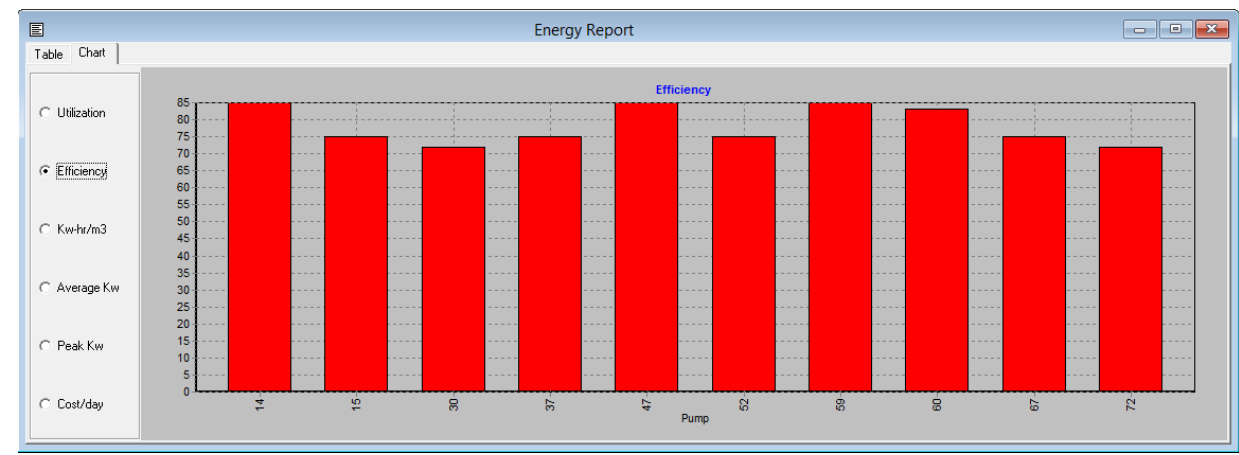

Fig. 7: Variation of the average working efficiency of pumps in the network.

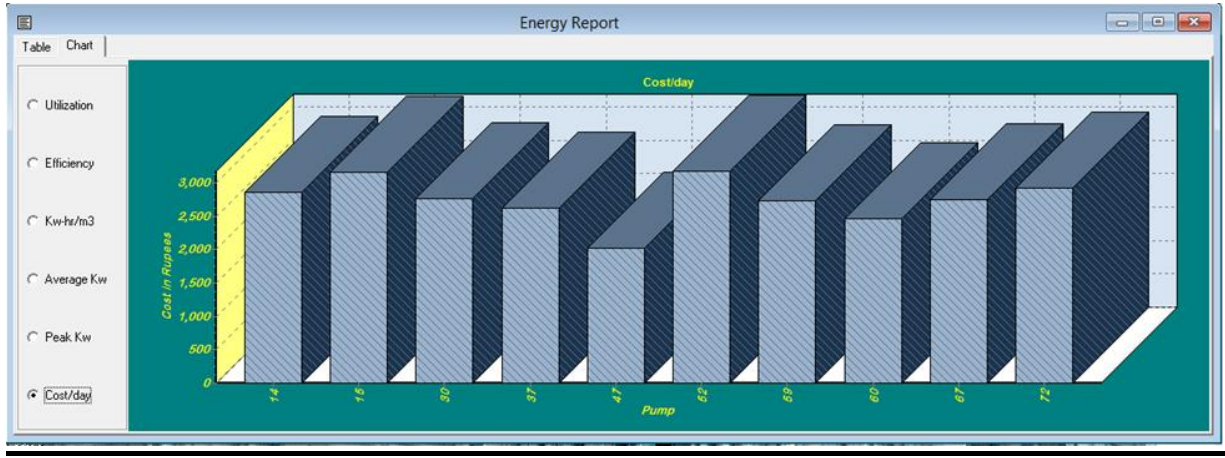

Fig. 8: 3-D graphical representation of cost analysis which is incurred by the pumps.

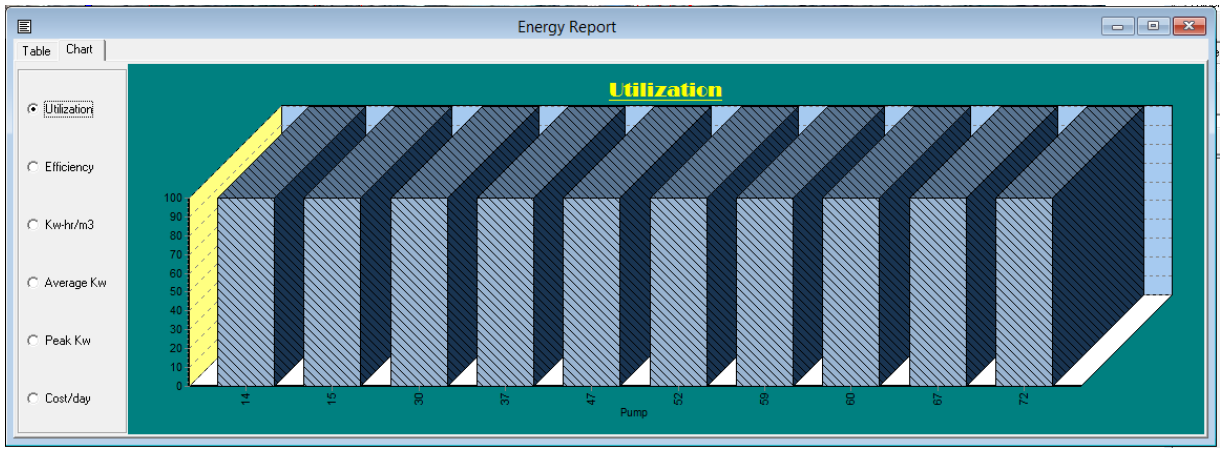

Fig. 9: Graph showing the data of utilization of each individual pump.

In case of present study, each pump shows full utilization means each individual pump takes water from the different source and there is no common source from which two or more pumps share the water to be pumped. This ensures the redundancy of the water distribution supply network. If one reservoir is short of storage or is out of use due to some reason or any pump goes out of order then the supply of water in the network not affected as a whole rather a part of the water supply and distribution network is affected. This fact that it gets affected over a region only adds to the redundancy and dependability of the system. Fig 9 depicts the percentage utilization of the pump. Percentage utilization refers to the percentage of the amount of water drawn through a particular reservoir. In case of present study, each pump shows full utilization means each individual pump takes water from the different source and there is no common source from which two or more pumps share the water to be pumped. This ensures the redundancy of the water distribution supply network. If one reservoir is short of storage or is out of use due to some reason or any pump goes out of order then the supply of water 
in the network not affected as a whole rather a part of the water supply and distribution network is affected. This fact that it gets affected over a region only adds to the redundancy and dependability of the system.

\section{Conclusion}

This study was to propose water supply distribution network carried out on the plan of BITS Pilani, Pilani campus. The model was designed and simulation was performed on EPANET. The result gave the efficiency and cost variation of the pumps and thereby of the whole network. The result obtained suggested that with the proposed network on the layout higher efficiency and lower economy was achieved and therefore this was the practical network to be adopted. The working efficiency of the different pump is listed in the fig. 8 graphically and it lies in the range of $70 \%-85 \%$ which is considered worthwhile in practical conditions. The cost analysis showed that the average cost of a pump per hour was found to be ranging from Rs.180 to Rs.350 and that running for a day amounts to Rs.3252 against that of the optimized network which totals to Rs.2747. This is approximately $18 \%$ lower than the actual cost incurred by the water supply distribution network. Hence, this study concludes as the proposed network is more efficient, economical and reliable it would form the basis if any improvement is required in the water supply distribution network.

Table 3: Comparison of Existing network and proposed network in terms of cost incurred.

\begin{tabular}{|l|c|c|}
\hline & $\begin{array}{l}\text { For Existing Network } \\
\text { (in Rupees) }\end{array}$ & $\begin{array}{l}\text { For Proposed Optimized } \\
\text { network (in Rupees) }\end{array}$ \\
\hline Avg. cost of one pump per hour & 218.28 & 196.22 \\
\hline Avg. cost of one pump per day & 3252.37 & 2747.06 \\
\hline Total cost of all pumps per hour & 2182.00 & 1962.19 \\
\hline Total cost of all pumps per day & 33086.60 & 27470.61 \\
\hline
\end{tabular}

\section{References}

[1] G. Anisha, A. Kumar, J. Ashok Kumar, P. Suvarna Raju, "Analysis and Design of Water Distribution Network Using EPANET for Chirala Municipality in Prakasam District of Andhra Pradesh," International Journal of Engineering and Applied Sciences (IJEAS), vol. 3, no. 4, 2016. ISSN: 2394-3661.

[2] Mohammed Ali I. Al-Hashim, Nassrin J. Al-Mansori, "Analysis And Evaluation Of The Potable Water Network And Water Quality In Al-Diwaniya City,” Diyala Journal Of Engineering Sciences, vol. 05, no. 01, pp.191-204, 2012.

[3] J. Gessler, "Optimization of pipe networks," in Proc. of the Ninth International. Symposium on Urban Hydrology, Hydraulics and Sediment Control, Univ. of Ky., Lexington, 1982.

[4] A. Shibu and M. Janga, "Least Cost Design Of Water Distribution Network Under Demand Uncertainty By Fuzzy Cross Entropy Method,” Journal of Environmental Research And Development, vol. 6, no. 3A, 2012.

[5] N. Jothiprakas, R. Muralidharan, "A Case Study on Pipe Network Analysis in An Educational Campus, ” Journal of Indian Water Works Association, vol. XXXXII, no.2, 2010. ISSN 0970-275X.

[6] N. Guth, P. Kingel, Demand Allocation In Water Distribution Network Modelling-A GIS Based Approach Using Vornoi Diagrams With Constraints.

[7] M. A. H. Abdy Sayyeda, R. Gupta, T. T. Tanyimboh, "Modeling Pressure Deficient Water Distribution Networks in EPANET," in Proceedings in Conference on Water Distribution System Analysis, pp. 626-631, 2014.

[8] I. Gupta, R. K. Khitoliya, S. Kumar, "Study of Water Distribution Network using EPANET," International Journal of Computational Engineering Research, vol. 3, no. 6, pp. 58-6, 2013.

[9] J. H. Vyas, N. J. Shrimali, M. A. Modi, "Optimization of Dhrafad Regional Water supply scheme using EPANET," International Journal of Innovative Research in Science, Engineering \& Technology, vol. 2, no. 10, pp. 5768-5773, 2013.

[10] K. Shital, M. Krunali, D. Mehta, V. Yadav, "Simulation of Existing Water Distribution Network by using EPANET: A Case Study of Surat City," GRD Journals, Global Research and Development Journal for Engineering, Recent Advances in Civil Engineering for Global Sustainability, 2016. e-ISSN: 2455-5703. 
[11] S. I Waikhom, D. J Mehta, "Optimization of Limbayat Zone Water Distribution System Using EPANET," International Research Journal of Engineering and Technology (IRJET), 2015. e-ISSN: 2395 -0056.

[12] H. B. Nielsen, "Methods for Analyzing Pipe Networks," Journal of Hydraulic Engineering, ASCE, vol. 115, no. 2, pp. 139-157, 1989. 